\title{
Características da Anatomia Foliar de Espécies de Braquiária E SUA RElaÇão COM a SEnSIbIlidade a HeRbicidas ${ }^{1}$
}

\author{
Characteristics of the Leaf Anatomy of Surinam Grass and Alexandergrass Related to Sensitivity \\ to Herbicides
}

MARQUES, R.P. ${ }^{2}$, RODELLA, R.A. ${ }^{3}$ e MARTINS, D. ${ }^{4}$

\begin{abstract}
RESUMO - O objetivo deste trabalho foi relacionar as características da anatomia foliar de Brachiaria decumbens (capim-braquiária) e Brachiaria plantaginea (capim-marmelada), em três estádios de desenvolvimento da planta, com a sensibilidade a herbicidas. A semeadura foi feita em vasos plásticos, contendo solo, mantidos em casa de vegetação. Foi amostrada a porção mediana do limbo da terceira folha expandida, a partir da base do colmo, compreendendo três estádios de desenvolvimento da planta: estádio 1 (com 4-6 folhas), estádio 2 (com 3-4 perfilhos) e estádio 3 (plantas adultas no início do florescimento). Foram quantificados os seguintes descritores anatômicos das regiões da quilha (nervura central) e da asa (porção entre a nervura central e a margem do limbo): área da secção transversal; porcentagens de epiderme das faces adaxial e abaxial, esclerênquima, bainha do feixe vascular, feixe vascular e parênquima; espessura da folha; distância entre os feixes vasculares; comprimento do estômato; e número de estômatos e de tricomas (curtos e longos). Os valores obtidos foram submetidos aos testes estatísticos multivariados de Análise de Agrupamento e Análise dos Componentes Principais. Os descritores avaliados permitiram diferenciar o estádio 3 de desenvolvimento da planta em relação aos demais, o qual pode ser considerado o menos sensivel à ação dos herbicidas aplicados em pós-emergência.
\end{abstract}

Palavras-chave: Brachiaria decumbens, Brachiaria plantaginea, análise multivariada, folha, gramíneas.

\begin{abstract}
The aim of this study was to relate the leaf anatomical characteristics of Brachiaria decumbens ('Surinam grass') and Brachiaria plantaginea ('Alexandergrass') to herbicide sensitivity, at three developmental stages. The plants were sown in plastic pots filled with agricultural soil and kept in a greenhouse. The blade median portion of the third-expanded leaf, counted from the stem basis, was sampled, considering three developmental phases: stage 1 (plants presenting 4-6 leaves), stage 2 (plants presenting 3-4 tillers) and, stage 3 (adult plants in the beginning of flowering). The following leaf anatomy descriptors were quantified in the region of the keel (midrib) and wing (a portion between the midrib and the blade margin): transversal section area; percentages of epidermal cells in the adaxial and abaxial surfaces, sclerenchyma, vascular bundle sheath, vascular bundle, and parenchyma; leaf thickness; distance between vascular bundles; stomatal length; number of stomata and trichome (short and long). The values obtained were analyzed using multivariate statistical tests (Cluster Analysis and Principal Component Analysis). The leaf quantitative anatomical descriptors allowed differentiating stage 3 from the other stages as the least sensitive to the action of post-emergence herbicides.
\end{abstract}

Keywords: Brachiaria decumbens, Brachiaria plantaginea, multivariate analysis, leaf, grasses.

Recebido para publicação em 4.11.2011 e aprovado em 11.5.2012.

2 Doutoranda em Agronomia, Dep. de Produção Vegetal, Faculdade de Ciências Agronômicas, Universidade Estadual Paulista FCA/UNESP, Fazenda Lageado, Caixa Postal 237, 18603-970 Botucatu-SP, <r.pmarques@yahoo.com.br>; ${ }^{3}$ Professor Assistente, Doutor, Dep. de Botânica, Instituto de Biociências de Botucatu, IBB/UNESP; ${ }^{4}$ Professor Livre Docente, Departamento de Produção Vegetal, FCA/UNESP, Botucatu-SP. 


\section{INTRODUÇÃO}

O controle feito com herbicidas aplicados em pós-emergência está sujeito à influência de fatores relacionados com o tamanho das plantas no instante da aplicação. Muitos estudos indicam que os herbicidas em pós-emergência são mais eficientes quando aplicados sobre plantas daninhas que estão nas fases iniciais de desenvolvimento; espécies do mesmo gênero podem comportar-se de maneira diferente em relação aos tratamentos (Devlin et al., 1991).

Em aplicações de pós-emergência, as folhas representam a principal rota de entrada dos herbicidas nas plantas. O estudo da anatomia foliar de espécies infestantes destaca-se como uma técnica essencial na identificação e descrição de estruturas que podem influenciar na absorção e no efeito dos herbicidas, além de auxiliar na caracterização de estruturas foliares (Ferreira et al., 2002, 2007).

Assim, abordagens anatômicas foliares de plantas daninhas contribuem com informações sobre a estrutura foliar, que podem estar relacionadas com a penetração diferencial de produtos aplicados sobre as folhas das plantas. De acordo com Procópio et al. (2003), a morfologia das folhas influencia a quantidade de produto interceptado e retido, porém é a anatomia foliar que determina a facilidade com que serão absorvidos.

Além disso, os herbicidas podem apresentar diferentes niveis de controle de plantas daninhas, em função de espécies presentes na área, do estádio de desenvolvimento, da dose do herbicida e das condições de aplicação e de ambiente. O controle eficiente de plantas daninhas com o uso de herbicidas em pósemergência depende, sobretudo, do estádio de desenvolvimento delas (Askew et al., 2000; Johnson \& Hoverstad, 2002). À medida que a aplicação for atrasada, há menor eficiência de controle, pelo fato de as plantas daninhas apresentarem maior desenvolvimento vegetativo e tolerância aos herbicidas.

Alguns trabalhos sobre características anatômicas das folhas de plantas daninhas vêm sendo realizados no Brasil (Ferreira et al., 2002; Tuffi Santos et al., 2004). No entanto, deve-se ressaltar que trabalhos relacionando o efeito de herbicidas aplicados em pós-emergência com o estádio de desenvolvimento de espécies de gramíneas infestantes e suas características anatômicas foliares são escassos ou quase inexistentes na literatura.

O objetivo deste trabalho foi relacionar as características da anatomia foliar de Brachiaria decumbens e Brachiaria plantaginea, em três estádios de desenvolvimento da planta, com a sensibilidade a herbicidas.

\section{MATERIAL E MÉTODOS}

O experimento foi conduzido utilizando-se as espécies Brachiaria decumbens (capimbraquiária) e Brachiaria plantaginea (capim marmelada), ambas consideradas plantas daninhas. As sementes de $B$. decumbens e de $B$. plantaginea foram semeadas em vasos plásticos de $4 \mathrm{~L}$ de capacidade, com cinco repetições, contendo solo e mantidos em casa de vegetação. Após a emergência, efetuou-se um desbaste, deixando-se cinco plântulas por vaso.

As análises anatômicas foliares foram realizadas amostrando-se a porção mediana do limbo da terceira folha expandida, contada a partir da base do colmo, compreendendo três estádios de desenvolvimento da planta: estádio 1 (plantas com 4-6 folhas no colmo, aos 15 dias após a emergência), estádio 2 (plantas com 3-4 perfilhos, aos 23 dias após a emergência) e estádio 3 (plantas adultas no início do florescimento, aos 48 dias após a emergência). As amostras foliares, com cinco repetições, foram fixadas em FAA 50 (formaldeído+ ácido acético + álcool 50\%) por 48 horas e conservadas em álcool 70\% (Johansen, 1940).

Posteriormente, essas amostras foram infiltradas com historresina (resina glicol-metacrilato), de acordo com a técnica empregada por Gerrits (1991). Realizaram-se cortes transversais do material foliar em micrótomo rotatório com 8 a $10 \mu \mathrm{m}$ de espessura, os quais foram corados com azul de toluidina 0,05\% (O’Brien et al., 1964) e, em seguida, montados em lâminas histológicas de vidro com resina sintética.

Foram feitas observações microscópicas das estruturas anatômicas das regiões da quilha (nervura central) e da asa (porção compreendida entre a nervura central e a margem 
do limbo), sendo os limites e os contornos dos tecidos desenhados com auxílio de microscópio de projeção (Costa et al., 2010). A seguir, as estruturas anatômicas dessas regiões foram quantificadas com auxílio de mesa digitalizadora, acoplada a um computador equipado com programa computacional específico (Costa et al., 2010).

Os descritores anatômicos foliares avaliados nas regiões da quilha e da asa foram: área da secção transversal; porcentagens de epiderme das faces adaxial e abaxial, esclerênquima, bainha do feixe vascular, feixe vascular e parênquima; espessura da folha; distância entre os feixes vasculares; comprimento do estômato; e número de estômatos e de tricomas (curtos e longos). Para determinação do comprimento do estômato e contagem de estômatos e de tricomas da superficie foliar, foi usada a técnica de impressão epidérmica, utilizando-se cola de secagem instantânea.

Os valores médios dos 23 descritores anatômicos foliares quantitativos de $B$. decumbens e B. plantaginea, em três estádios de desenvolvimento da planta, foram submetidos aos testes estatísticos multivariados de Análise de Agrupamento e Análise de Componentes Principais, com a finalidade de agrupar as espécies e os respectivos estádios de desenvolvimento de acordo com o seu grau de similaridade, bem como verificar a capacidade discriminatória dos descritores no processo de formação dos agrupamentos.

\section{RESULTADOS E DISCUSSÃO}

Os valores médios referentes aos 23 descritores anatômicos quantitativos do limbo foliar, considerando-se as regiões da nervura central (quilha) e da porção compreendida entre a nervura central e a margem do limbo (asa) de $B$. decumbens e $B$. plantaginea, em três estádios de desenvolvimento da planta, estão apresentados nas Tabelas 1, 2 e 3.

Na Tabela 4 são mostrados os coeficientes de correlação entre os 23 descritores anatômicos foliares quantitativos das duas espécies de Brachiaria estudadas, nos três estádios de desenvolvimento da planta, e os dois primeiros componentes principais $\left(\mathrm{Y}_{1}\right.$ e $\left.\mathrm{Y}_{2}\right)$. Esses componentes, no conjunto, foram responsáveis por $92,43 \%$ da informação acumulada pelos descritores avaliados, podendo ser indicadores eficientes de dissimilaridade.

O dendrograma resultante da análise de agrupamento (Figura 1) e a dispersão gráfica referente à análise dos componentes principais (Figura 2) mostraram que os descritores anatômicos com maior poder de discriminação foram os responsáveis pelos agrupamentos formados entre as espécies e os estádios de desenvolvimento avaliados, constituindo quatro grupos principais, em nível de 0,24 na escala de distância de similaridade (Figura 2). O primeiro grupo foi formado pelo estádio 1 (planta com 4-6 folhas no colmo, 15 dias após a emergência) e pelo estádio 2 (planta com 3-4 perfilhos, 23 dias após a emergência) de $B$. decumbens; o segundo grupo constituiu-se dos estádios 1 e 2 de B. plantaginea; e o terceiro e o quarto grupo compreenderam apenas o estádio 3 (planta adulta no início do florescimento, 48 dias após a emergência), respectivamente, de $B$. decumbens e de $B$. plantaginea. Verifica-se também, pela Figura 2, que o primeiro e o segundo grupo, em nível de 0,30 na escala de distância, podem se agrupar, formando um grupo sem discriminação entre os estádios 1 e 2 de desenvolvimento, nas duas espécies de Brachiaria.

A análise dos coeficientes de correlação do componente principal $\mathrm{Y}_{1}$ (Tabela 4), associados à dispersão gráfica (Figura 2), permite constatar que os estádios 1 e 2 de desenvolvimento apresentaram alto grau de dissimilaridade em relação ao estádio 3, para as duas espécies de Brachiaria estudadas. Assim, o estádio 3 pode ser diferenciado dos demais, por apresentar maior área da secção transversal da quilha, maior porcentagem (\%) de esclerênquima da quilha e asa, maior porcentagem de parênquima da quilha, maior porcentagem de feixe vascular da asa, maior comprimento do estômato da face adaxial, maior número de estômatos das faces adaxial e abaxial, maior número de tricomas curtos das faces adaxial e abaxial, menor porcentagem de epiderme adaxial da quilha e abaxial da quilha e asa, menor porcentagem de bainha do feixe vascular da quilha e asa e menor distância entre feixes vasculares. Essas características, presentes nas folhas do estádio 3, demonstram que estas se encontram mais desenvolvidas que as folhas dos estádios 1 e 2 de desenvolvimento. 
Tabela 1 - Valores médios dos descritores anatômicos foliares quantitativos da região da nervura central (quilha) de Brachiaria decumbens e Brachiaria plantaginea, em três estádios (E1-E2-E3) de desenvolvimento da planta

\begin{tabular}{|l|r|r|r|r|r|r|}
\hline \multirow{2}{*}{ Descritor anatômico quantitativo } & \multicolumn{3}{|c|}{ B. decumbens } & \multicolumn{3}{c|}{ B. plantaginea } \\
\cline { 2 - 7 } & \multicolumn{1}{|c|}{ E1 } & E2 & E3 & E1 & E2 & E3 \\
\hline Área $\left(10^{-3} \mathrm{~mm}^{2}\right)$ da secção transversal da quilha & 91,68 & 143,58 & 263,82 & 105,86 & 149,49 & 393,79 \\
\hline \% Epiderme adaxial da quilha & 14,51 & 9,78 & 3,44 & 18,68 & 13,79 & 1,23 \\
\hline \% Epiderme abaxial da quilha & 7,94 & 7,29 & 4,31 & 8,68 & 6,19 & 2,45 \\
\hline \% Esclerênquima da quilha & 5,66 & 5,61 & 6,27 & 2,77 & 3,59 & 6,26 \\
\hline \% Bainha do feixe da quilha & 28,55 & 31,95 & 18,71 & 29,26 & 36,04 & 11,79 \\
\hline \% Feixe vascular da quilha & 6,84 & 6,48 & 6,93 & 5,36 & 5,59 & 5,83 \\
\hline \% Parênquima da quilha & 36,50 & 38,89 & 60,34 & 35,25 & 44,80 & 72,44 \\
\hline
\end{tabular}

E1: planta com 4-6 folhas no colmo (15 dias após emergência). E2: planta com 3-4 perfilhos (23 dias após a emergência). E3: planta adulta no início do florescimento (48 dias após a emergência).

Tabela 2 - Valores médios dos descritores anatômicos foliares quantitativos da região compreendida entre a nervura central e a margem do limbo (asa) de Brachiaria decumbens e Brachiaria plantaginea, em três estádios (E1-E2-E3) de desenvolvimento da planta

\begin{tabular}{|l|r|r|r|r|r|r|}
\hline \multirow{2}{*}{ Descritor anatômico quantitativo } & \multicolumn{3}{c|}{ B. decumbens } & \multicolumn{3}{c|}{ B. plantaginea } \\
\cline { 2 - 7 } & E1 & E2 & E3 & E1 & E2 & E3 \\
\hline \% Epiderme adaxial da asa & 14,81 & 14,86 & 11,17 & 15,94 & 15,30 & 14,77 \\
\hline \% Epiderme abaxial da asa & 8,98 & 8,96 & 6,25 & 10,05 & 8,04 & 6,53 \\
\hline \% Esclerênquima da asa & 1,50 & 0,96 & 3,22 & 0,75 & 0,96 & 5,31 \\
\hline \% Bainha do feixe da asa & 34,16 & 36,78 & 31,03 & 35,34 & 36,46 & 28,88 \\
\hline \% Feixe vascular da asa & 3,90 & 4,80 & 19,99 & 3,66 & 4,27 & 11,49 \\
\hline \% Parênquima da asa & 36,65 & 33,64 & 37,34 & 34,26 & 34,97 & 33,02 \\
\hline Espessura $(\mu \mathrm{m})$ da folha & 148,77 & 185,39 & 141,26 & 164,42 & 173,14 & 150,72 \\
\hline Distância $(\mu \mathrm{m})$ entre feixe vascular & 217,44 & 257,07 & 176,92 & 209,63 & 296,50 & 180,43 \\
\hline
\end{tabular}

E1: planta com 4-6 folhas no colmo (15 dias após emergência). E2: planta com 3-4 perfilhos (23 dias após a emergência). E3: planta adulta no início do florescimento (48 dias após a emergência).

Tabela 3 - Valores médios dos descritores anatômicos foliares quantitativos da superfície foliar de Brachiaria decumbens e Brachiaria plantaginea, em três estádios (E1-E2-E3) de desenvolvimento da planta

\begin{tabular}{|l|r|r|r|r|r|r|}
\hline \multirow{2}{*}{ Descritor anatômico quantitativo } & \multicolumn{3}{c|}{ B. decumbens } & \multicolumn{3}{c|}{ B. plantaginea } \\
\cline { 2 - 7 } & $\mathrm{E} 1$ & $\mathrm{E} 2$ & $\mathrm{E} 3$ & \multicolumn{1}{c|}{ E1 } & E2 & E3 \\
\hline Comprimento $(\mu \mathrm{m})$ do estômato da face adaxial & 25,78 & 26,49 & 27,88 & 23,20 & 25,63 & 28,50 \\
\hline Comprimento $(\mu \mathrm{m})$ do estômato da face abaxial & 30,50 & 29,44 & 30,55 & 36,65 & 36,60 & 31,34 \\
\hline Número por $\mathrm{mm}^{2}$ de estômatos da face adaxial & 77,70 & 57,18 & 130,47 & 92,25 & 94,68 & 148,44 \\
\hline Número por $\mathrm{mm}^{2}$ de estômatos da face abaxial & 63,45 & 55,21 & 129,88 & 66,47 & 59,18 & 150,31 \\
\hline Número por $\mathrm{mm}^{2}$ de tricomas curtos da face adaxial & 0,00 & 0,00 & 5,97 & 0,00 & 0,00 & 8,06 \\
\hline Número por $\mathrm{mm}^{2}$ de tricomas curtos da face abaxial & 14,51 & 12,97 & 24,32 & 14,59 & 14,42 & 22,70 \\
\hline Número por $\mathrm{mm}^{2}$ de tricomas longos da face adaxial & 0,86 & 0,47 & 1,28 & 0,00 & 0,00 & 0,00 \\
\hline Número por $\mathrm{mm}^{2}$ de tricomas longos da face abaxial & 1,10 & 0,82 & 0,94 & 0,00 & 0,00 & 0,00 \\
\hline
\end{tabular}

E1: planta com 4-6 folhas no colmo (15 dias após emergência). E2: planta com 3-4 perfilhos (23 dias após a emergência). E3: planta adulta no início do florescimento (48 dias após a emergência).

A maior porcentagem de esclerênquima foi constatada no estádio 3 de desenvolvimento, uma vez que plantas adultas apresentam maior lignificação das paredes celulares, influenciando na redução da penetração de herbicidas. Segundo Alves de 
Tabela 4 - Coeficientes de correlação entre os 23 descritores anatômicos foliares quantitativos de Brachiaria decumbens e Brachiaria plantaginea, em três estádios (E1-E2-E3) de desenvolvimento da planta, e os dois primeiros componentes principais $\left(\mathrm{Y}_{1}\right.$ e $\left.\mathrm{Y}_{2}\right)$

\begin{tabular}{|c|c|c|}
\hline Descritor anatômico quantitativo & $Y_{1}$ & $\mathrm{Y}_{2}$ \\
\hline Área da secção transversal da quilha & $-0,9419$ & $-0,2990$ \\
\hline$\%$ Epiderme adaxial da quilha & 0,9426 & $-0,0777$ \\
\hline \% Epiderme abaxial da quilha & 0,9359 & 0,2156 \\
\hline \% Esclerênquima da quilha & $-0,7238$ & 0,5259 \\
\hline$\%$ Bainha do feixe vascular da quilha & 0,9342 & 0,0657 \\
\hline$\%$ Feixe vascular da quilha & $-0,2757$ & 0,9465 \\
\hline \% Parênquima da quilha & $-0,9616$ & $-0,2375$ \\
\hline$\%$ Epiderme adaxial da asa & 0,6518 & $-0,6078$ \\
\hline$\%$ Epiderme abaxial da asa & 0,9176 & $-0,0481$ \\
\hline \% Esclerênquima da asa & $-0,9561$ & $-0,1736$ \\
\hline$\%$ Bainha do feixe vascular da asa & 0,9420 & 0,0646 \\
\hline$\%$ Feixe vascular da asa & $-0,8665$ & 0,2844 \\
\hline \% Parênquima da asa & $-0,0409$ & 0,7391 \\
\hline Espessura da folha & 0,6509 & $-0,2675$ \\
\hline Distância entre feixe vascular & 0,7085 & $-0,1681$ \\
\hline Comprimento do estômato da face adaxial & $-0,8670$ & 0,1930 \\
\hline Comprimento do estômato da face abaxial & 0,4521 & $-0,6858$ \\
\hline Número por $\mathrm{mm}^{2}$ de estômatos da face adaxial & $-0,8775$ & $-0,3337$ \\
\hline Número por $\mathrm{mm}^{2}$ de estômatos da face abaxial & $-0,9799$ & $-0,1286$ \\
\hline Número por $\mathrm{mm}^{2}$ de tricomas curtos da face adaxial & $-0,9893$ & $-0,1288$ \\
\hline Número por $\mathrm{mm}^{2}$ de tricomas curtos da face abaxial & $-0,9594$ & 0,0319 \\
\hline Número por $\mathrm{mm}^{2}$ de tricomas longos da face adaxial & $-0,2754$ & 0,9380 \\
\hline Número por $\mathrm{mm}^{2}$ de tricomas longos da face abaxial & $-0,0179$ & 0,9878 \\
\hline Informação retida (\%) & 63,33 & 29,10 \\
\hline Informação acumulada (\%) & 63,33 & 92,43 \\
\hline
\end{tabular}

Brito \& Deschamps (2001), o incremento no teor de lignina pode estar associado ao espessamento da parede celular, principalmente da parede secundária. A presença da parede secundária pode limitar a translocação de herbicidas em plantas mais velhas, por ser menos permeável e mais espessa que a parede primária, necessitando da aplicação de maiores doses de herbicidas para seu controle. Isso reforça a necessidade de o controle em pósemergência dessas espécies ser realizado nos estádios iniciais de desenvolvimento, conforme o trabalho de Marques et al. (2011), que estudaram o manejo das mesmas espécies ora avaliadas e nos mesmos estádios de desenvolvimento.

O estádio de planta adulta apresentou, em ambas as espécies, menor distância entre os feixes vasculares, o que pode facilitar a translocação de herbicidas através dos feixes, pela proximidade em que se encontram. Entretanto, a lignificação que ocorre nesse estádio de desenvolvimento reduz inclusive a absorção de herbicidas e, consequentemente, menor quantidade do produto alcança os feixes vasculares para posterior movimentação dentro da folha.

A análise dos coeficientes de correlação do componente principal $\mathrm{Y}_{2}$ (Tabela 4), associados à dispersão gráfica (Figura 2), permite constatar que, nos três estádios de desenvolvimento, $B$. decumbens apresentou alta dissimilaridade em relação a $B$. plantaginea. Assim, B. decumbens pode ser diferenciada de $B$. plantaginea por apresentar menor porcentagem de epiderme adaxial da asa, maior 


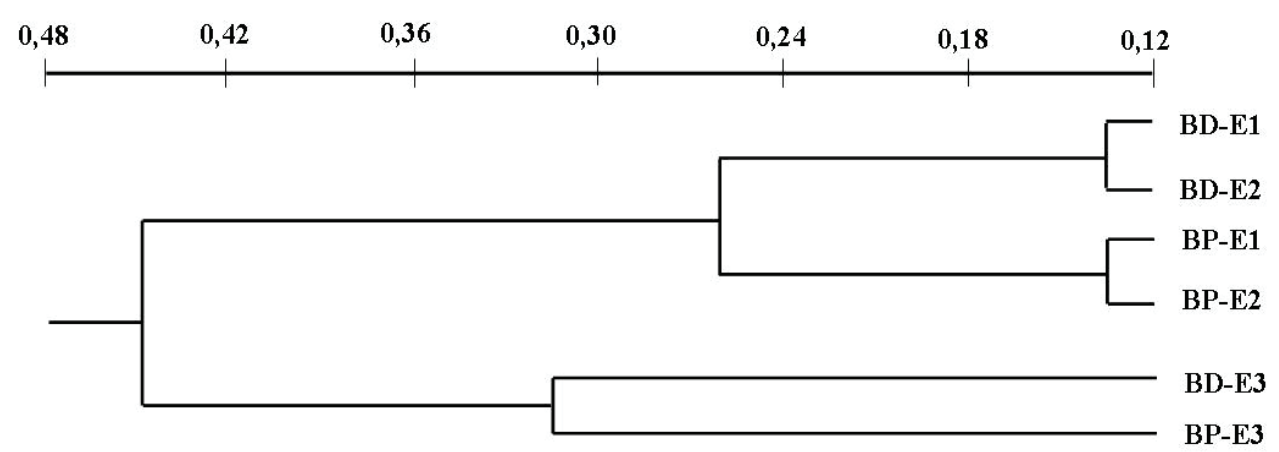

Figura 1 - Dendrograma resultante da análise de agrupamento dos 23 descritores anatômicos foliares quantitativos, utilizandose a distância euclidiana média entre as duas espécies de Brachiaria e os três estádios (E1-E2-E3) de desenvolvimento da planta. BD: B. decumbens. BP: B. plantaginea. E1: planta com 4-6 folhas no colmo (15 dias após emergência). E2: planta com 3-4 perfilhos (23 dias após a emergência). E3: planta adulta no início do florescimento (48 dias após a emergência).

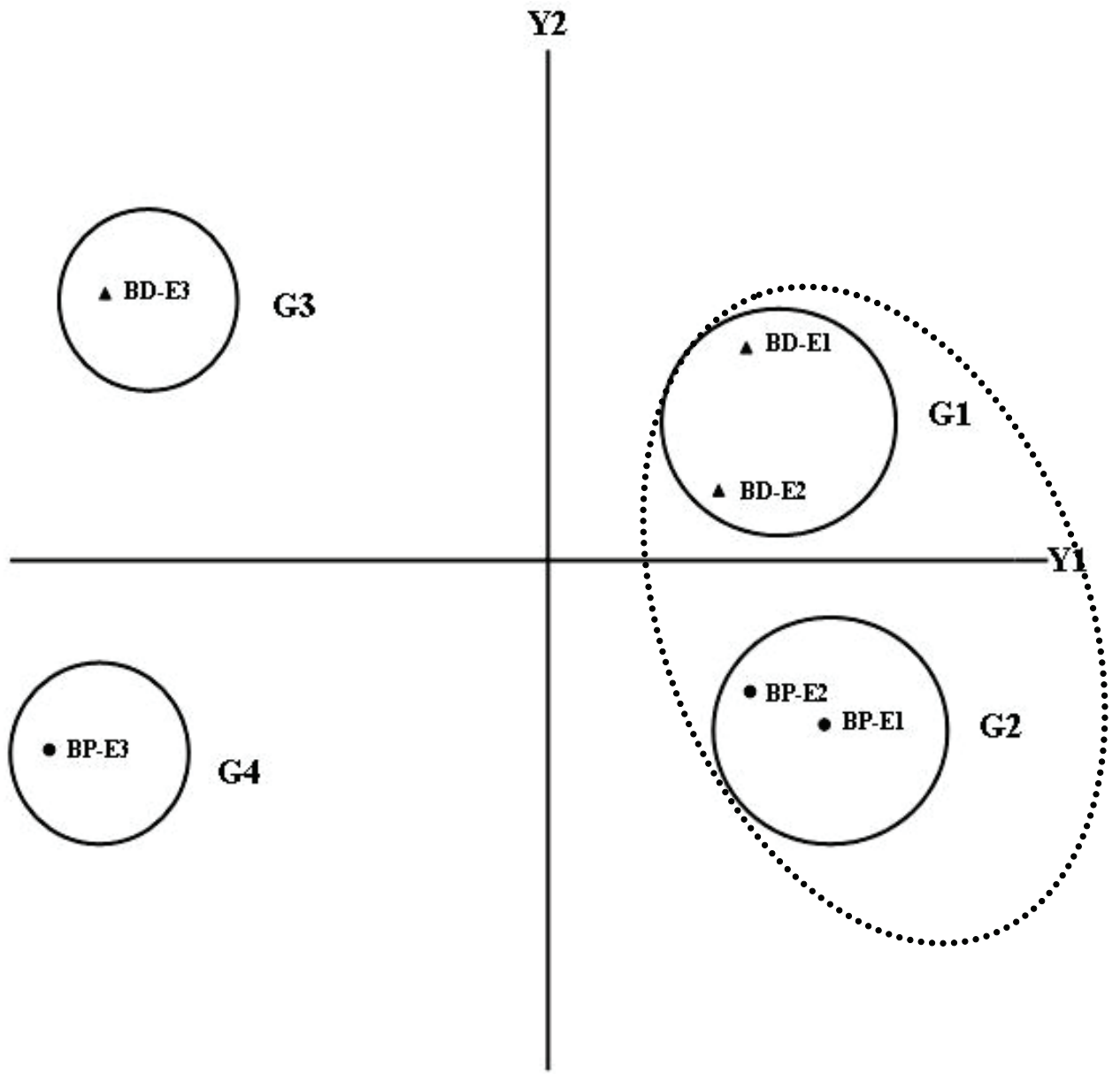

Figura 2 - Dispersão gráfica das duas espécies de Brachiaria e dos três estádios (E1-E2-E3) de desenvolvimento da planta, utilizando-se os dois primeiros componentes principais $\left(\mathrm{Y}_{1}\right.$ e $\left.\mathrm{Y}_{2}\right)$, para o conjunto dos 23 descritores anatômicos foliares quantitativos. BD: $B$. decumbens. BP: B. plantaginea. E1: planta com 4-6 folhas no colmo (15 dias após emergência). E2: planta com 3-4 perfilhos (23 dias após a emergência). E3: planta adulta no início do florescimento (48 dias após a emergência). G1: grupo 1. G2: grupo 2. G3: grupo 3. G4: grupo 4. 
porcentagem de feixe vascular da quilha e asa, maior porcentagem de parênquima da asa e maior número de tricomas longos das faces adaxial e abaxial.

Costa et al. (2006) diferenciaram espécies daninhas aquáticas com o emprego da análise multivariada, constatando que $B$. mutica, $B$. subquadripara e Panicum repens apresentaram maiores valores de feixe vascular, bainha do feixe, esclerênquima e número de tricomas, bem como menores valores para número de estômatos e espessura da folha, do que Eichhornia crassipes, Heteranthera reniformis, Typha subulata e Enhydra anagallis, o que as caracteriza como espécies com maior dificuldade de controle químico.

Dessa forma, no estádio 3 de desenvolvimento as espécies apresentaram maior porcentagem de esclerênquima, de feixes vasculares e de parênquima, dificultando a absorção e o transporte da calda herbicida na folha; portanto, esse estádio pode ser considerado menos sensivel aos efeitos de herbicidas do que os estádios iniciais de desenvolvimento das espécies estudadas.

Em $B$. decumbens e $B$. plantaginea ocorrem camadas esclerenquimáticas subepidérmicas, localizadas nas porções adaxial e abaxial do mesofilo, as quais dificultam o rompimento da epiderme do restante da folha, conferindo, dessa forma, maior resistência aos danos mecânicos e químicos.

De acordo com Osmond \& Smith (1976), como as células da bainha do feixe vascular são lignificadas e também podem apresentar suberina, o deslocamento das moléculas do herbicida das células do mesofilo para as células da bainha do feixe é prejudicado e mais lento nos estádios mais avançados de desenvolvimento do que em estádios iniciais de desenvolvimento da planta.

O maior número de estômatos e de tricomas nas faces adaxial e abaxial de $B$. decumbens e $B$. plantaginea, nos estádios mais avançados de desenvolvimento, pode não ser um fator relevante na eficiência do controle químico em pós-emergência, visto que a influência dessas estruturas sobre a absorção de herbicidas tem apresentado muitas controvérsias.
Procópio et al. (2003) identificaram, como principais barreiras à penetração de herbicidas, a baixa densidade estomática da face adaxial em folhas de Galinsoga parviflora e Ipomoea cairica, bem como a alta densidade de tricomas e a baixa densidade de estômatos na face adaxial foliar de Coniza bonariensis.

Greene \& Bukovac (1974) e Stock \& Holloway (1993) consideram que, em plantas daninhas com alta densidade estomática, o uso de surfatantes organossiliconados pode aumentar a penetração estomática e, assim, contribuir para o melhor controle de plantas daninhas. Ferreira et al. (2002) e Procópio et al. (2003) recomendaram, para o controle de plantas daninhas que apresentam estômatos com grande comprimento do ostíolo, o uso de organossiliconados adicionados à calda de pulverização de herbicidas, o que facilita a sua absorção, por quebrar a tensão superficial da calda do herbicida.

Ferreira et al. (2007) verificaram também que o clone de cana-de-açúcar, mais sensivel à mistura de herbicidas, apresentou maior densidade de estômatos e de tricomas em ambas as faces, epiderme menos espessada na face adaxial e estômatos com maior comprimento de ostíolos nas duas faces do limbo foliar. Tuffi-Santos et al. (2009) consideraram os estômatos uma via improvável de absorção de glyphosate em três clones de eucalipto, uma vez que o maior número de estômatos encontra-se na face abaxial das folhas.

A eficiência da absorção de herbicidas pelos tricomas e a translocação destes para as células epidérmicas ainda são parcialmente desconhecidas (Hess \& Falk, 1990). Todavia, são poucos os relatos de que os tricomas sejam um bom caminho para a entrada de herbicidas, havendo, portanto, uma relação negativa entre a aderência dos herbicidas nos tricomas e a eficácia desses produtos.

Segundo Costa et al. (2010), as estruturas anatômicas da folha relativas a epiderme, feixe vascular, bainha do feixe vascular, parênquima, esclerênquima, estômatos, tricomas e espessura da folha podem influenciar na deposição, retenção, absorção e translocação de soluções aplicadas sobre as folhas, funcionando como barreiras, e, dessa forma, estar associadas à maior ou menor resistência 
ou tolerância de determinada planta aos produtos fitossanitários.

Assim, as estruturas anatômicas foliares podem estar relacionadas com a maior ou menor sensibilidade da planta aos herbicidas, sendo decisivas para o manejo químico. Contudo, pouco se conhece sobre a contribuição de cada caráter estrutural do limbo foliar no processo de absorção e translocação de herbicidas.

A análise dos descritores anatômicos permitiu diferenciar os três estádios de desenvolvimento da planta, sendo o estádio 3 mais discriminante que os estádios 1 e 2 , de modo que o estádio 3, em ambas as espécies, foi caracterizado como mais difícil de ser controlado por meio do uso de herbicidas aplicados em pós-emergência, ou seja, pode ser considerado menos sensivel a herbicidas.

\section{LITERATURA CITADA}

ALVES DE BRITO, C. J. F.; DESCHAMPS, F. C. Caracterização anatômica em diferentes frações de cultivares de capim-elefante (Pennisetum purpureum Schumach.). R. Bras. Zootec., v. 30, n. 5, p. 1409-1417, 2001.

ASKEW, S. D.; SHAW, D. R.; STREET, J. E. Graminicide application timing influences red rice (Oryza sativa) control and seedhead reduction in soybean (Glycine max). Weed Technol., v. 14, n. 1, p. 176-181, 2000.

COSTA, N. V. RODELLA, R. A.; MARTINS, D. Diferenciação de espécies daninhas aquáticas pela análise multivariada de caracteres estruturais foliares.

Planta Daninha, v. 24, n. 1, p. 13-20, 2006.

COSTA, N. V. et al. Efeito do trinexapac-ethyl na anatomia foliar de quatro espécies de grama. Planta Daninha, v. 28, n. 3, p. 551-560, 2010.

DELVLIN, D. L.; LONG, J. H.; MADDUX, L. D. Using reduced rates of postemergence herbicides in soybeans (Glycine max). Weed Technol., v. 5, n. 4, p. 834-840, 1991.

FERREIRA, E. A. et al. Estudos anatômicos de folhas de plantas daninhas. II. Bidens pilosa, Emilia sonchifolia, Ageratum conyzoides e Sonchus asper. Planta Daninha, v. 20, n. 3, p. 327-335, 2002.
FERREIRA, E. A. et al. Leaf blade quantitative anatomy of sugarcane cultivars and clones. Planta Daninha, v. 25, n. 1, p. 25-34, 2007.

GERRITS, P. O. The application of glycol metacrylate in histotechnology: some fundamental principle. Germany. Leica Gmgh, 1991.80 p.

GREENE, D. W., BUKOVAC, M. J. Stomatal penetration: effect of surfactants and role in foliar absorption. Am. J. Bot., v. 61, n. 1, p. 101-6, 1974.

HESS, F. D.; FALK, R. H. Herbicide deposition on leaf surfaces. Weed Sci., v. 38, n 3, p. 280-288, 1990.

JOHANSEN, D. A. Plant microtechnique. New York: McGrow-Hill Book, 1940. 523 p.

JOHNSON, G. A.; HOVERSTAD, T. R. Effect of row spacing and herbicide application timing on weed control and grain yield in corn (Zea mays). Weed Technol., v. 16, n. 3, p. 548-553, 2002.

MARQUES, R. P.; RODELLA, R. A.; MARTINS, D. Controle químico em pós-emergência de espécies de Brachiaria em três estádios vegetativos. Arq. Int. Biol., v.78, n. 3, p. 409-416, 2011.

O'BRIEN, T. P.; FEDER, N.; McCULLY, M. E.

Polychromatic staining of plant cellular wall by toluidine blue. Protoplasma, v. 59, n. 1, p. 368-373, 1964.

OSMOND, C. B.; SMITH, F. A. Symplatic transport of metabolites during C4-photosynthesis. In: GUNNING, B. E. S.; ROBARDS, A. W. (Eds.). Intercellular communication in plants: studies on plasmodesmata. New York: SpringerWerlag, 1976. p. 229-241.

PROCÓPIO, S. O. et al. Estudos anatômicos de folhas de plantas daninhas de grande ocorrência no Brasil. III. Galinsoga parviflora, Crotalaria incana, Conyza bonariensis e Ipomoea cairica. Planta Daninha, v. 21, n. 1, p. 1-9, 2003.

STOCK, D.; HOLLAWAY, P. J. Possible mechanisms for surfactant-induced foliar uptake of agrochemicals. Pestic. Sci., v. 38, n. 2/3, p. 165-177, 1993.

TUFFI SANTOS, L. D. et al. Leaf anatomy and morphometry in three eucalypt clones treated with glyphosate. Braz. J. Biol., v. 69, n. 1, p. 129-136, 2009.

TUFFI SANTOS, L. D. et al. Efeito do glyphosate sobre a morfoanatomia das folhas e do caule de Commelina diffusa e C. benghalensis. Planta Daninha, v. 22, n. 1, p. 101-108, 2004. 